\title{
Low-density lipoprotein receptor-related protein in metalloproteinase-mediated pathologies: recent insights
}

This article was published in the following Dove Press journal:

Metalloproteinases In Medicine

II February 2015

Number of times this article has been viewed

\author{
Hervé Emonard' \\ Etienne Marbaix ${ }^{2}$ \\ I"Matrice Extracellulaire et \\ Dynamique Cellulaire" Unit, Centre \\ National de Recherche Scientifique \\ (CNRS) Unité Mixte de Recherche \\ (UMR) 7369, Université de Reims \\ Champagne-Ardenne, Laboratoire \\ SiRMa, Reims, France; ${ }^{2}$ Institut de \\ Duve, Université catholique de \\ Louvain, Bruxelles, Belgique
}

\begin{abstract}
Low-density lipoprotein receptor-related protein (LRP)-1, LRP-1b, LRP-2, LRP-5, and LRP-6 mediate the endocytosis of metalloproteinases and inhibitors and/or promote the expression of metalloproteinases. These properties confer important and complex roles in the development of pathologies related to an intense proteolytic degradation of the cellular microenvironment. The cell surface levels of the identified endocytic receptors, LRP-1, LRP-1b, and LRP-2, are themselves regulated by metalloproteinases. The released extra- and intracellular domains may also exert functions in these pathologies.
\end{abstract}

Keywords: LRP, MMP, ADAM, ADAMTS

\section{Introduction}

Pathologies related to metalloproteinase activities represent an important part of biomedical research, yielding about 20,000 citations in PubMed. To understand the molecular mechanisms by which metalloproteinases mediate these pathologies represents the most important and exciting challenge for the development of new therapeutic strategies. In addition to regulation at both the expression and secretion levels, metalloproteinases can be further controlled. ${ }^{1}$ Thus, metalloproteinases are generally synthesized as inactive proenzymes and must be activated to be proteolytically efficient. Once activated, the metalloproteinases are inhibited by broad spectrum or specific inhibitors. An additional and efficient mechanism of control of metalloproteinases is the endocytic clearance mediated by members of the low-density lipoprotein (LDL) receptor (LDLR) family, LDLR-related proteins (LRPs). In addition to their endocytic activities, some of them exhibit signaling properties that can modulate the expression of some metalloproteinases.

After a brief description of the LDLR family, we focus this review on the LDLR family members involved in the regulation of metalloproteinase activity and/or expression, their role in the development of pathologies associated to metalloproteinase activities, and their own regulation by a shedding process mediated by metalloproteinases.

Correspondence: Hervé Emonard Laboratoire SiRMa, Campus Moulin de la Housse, Bât 18 , Chemin des Rouliers, BP 1039, 51687 Reims cedex 2, France Tel +33326918361 $\mathrm{Fax}+33326918366$ Email herve.emonard@univ-reims.fr

\section{General features of the LDLR family}

The LDLR family consists of membrane receptors involved in the endocytosis of a variety of ligands, most of which are lipoproteins. ${ }^{2}$ In humans, this family includes LDLR, ${ }^{3}$ VLDLR, ${ }^{4}$ LRP- $1,{ }^{5}$ LRP-1b, ${ }^{6}$ glycoprotein 330 (gp330)/megalin/ LRP-2, ${ }^{7}$ LRP-3 (closely resembles ST7/LRP-12), ${ }^{8,9}$ MEGF7/LRP-4, ${ }^{10}$ LRP-5, ${ }^{11}$ 
LRP-6, ${ }^{12}$ LRP-7, ${ }^{13}$ apoER2/LRP-8, ${ }^{14}$ LRP-9, ${ }^{15}$ LRP-10, ${ }^{16}$ and sorLA/LR11. ${ }^{17}$ They are type I membrane proteins that contain a single transmembrane-spanning domain with the exception of LRP-4, which is a type II membrane protein. ${ }^{10}$ They all share additional common modules characteristic of the LDLR family (epidermal growth factor [EGF] repeats, LDLR ligand-binding repeats, cytoplasmic domain) and exhibit both endocytic and signaling proper$\operatorname{ties}^{18}$ (Figure 1).

\section{Members of the LDLR family regulate metalloproteinase activity}

Until now, only LRP-1, LRP-1b, LRP-2, LRP-5, and LRP-6 have been demonstrated to regulate the level of metalloproteinases or their inhibitors, either by endocytosing them or by modulating their expression.

\section{Regulation of metalloproteinase activity by endocytosis}

Among the five members of the LDLR family that modulate metalloproteinase activity, only LRP-1, LRP-2, and LRP-1b mediate endocytosis of metalloproteinases or their inhibitors.

\section{LRP-I}

LRP-1, previously identified as an $\alpha_{2}$-macroglobulin receptor, ${ }^{19}$ is the first member of the protein family related to LDLR. ${ }^{20}$ It is synthesized as a $600 \mathrm{kDa}$ single-chain protein cleaved by a furin-like protease in the trans-Golgi compartment into a $515 \mathrm{kDa} \alpha$-chain and an $85 \mathrm{kDa} \beta$-chain that remain noncovalently associated. The extracellular $\alpha$ chain harbors four LDLR ligand-binding repeats that interact with about 40 ligands, whereas the transmembrane $\beta$-chain contains an extracellular portion, a transmembrane domain, and a short cytoplasmic tail that includes two NPxY motifs for triggering endocytosis and recruiting adaptor and signaling proteins. ${ }^{21}$

LRP-1 regulates extracellular proteolytic activities by mediating the endocytic clearance of all active proteinases (including metalloproteinases) bound to the pan-proteinase inhibitor $\alpha_{2}$-macroglobulin. ${ }^{19}$ More specifically, LRP-1 endocytoses members of the matrix metalloproteinase (MMP) family, MMP-2, MMP-9, and MMP-13, and members of the adamalysin-like metalloproteinase with thrombospondin (TSP) motifs (ADAMTS) family, ADAMTS-4 and ADAMTS-5. ${ }^{22}$ In addition, it also endocytoses members of the tissue inhibitor of metalloproteinases (TIMP) family, TIMP-1, TIMP-2, and TIMP-3. ${ }^{22}$

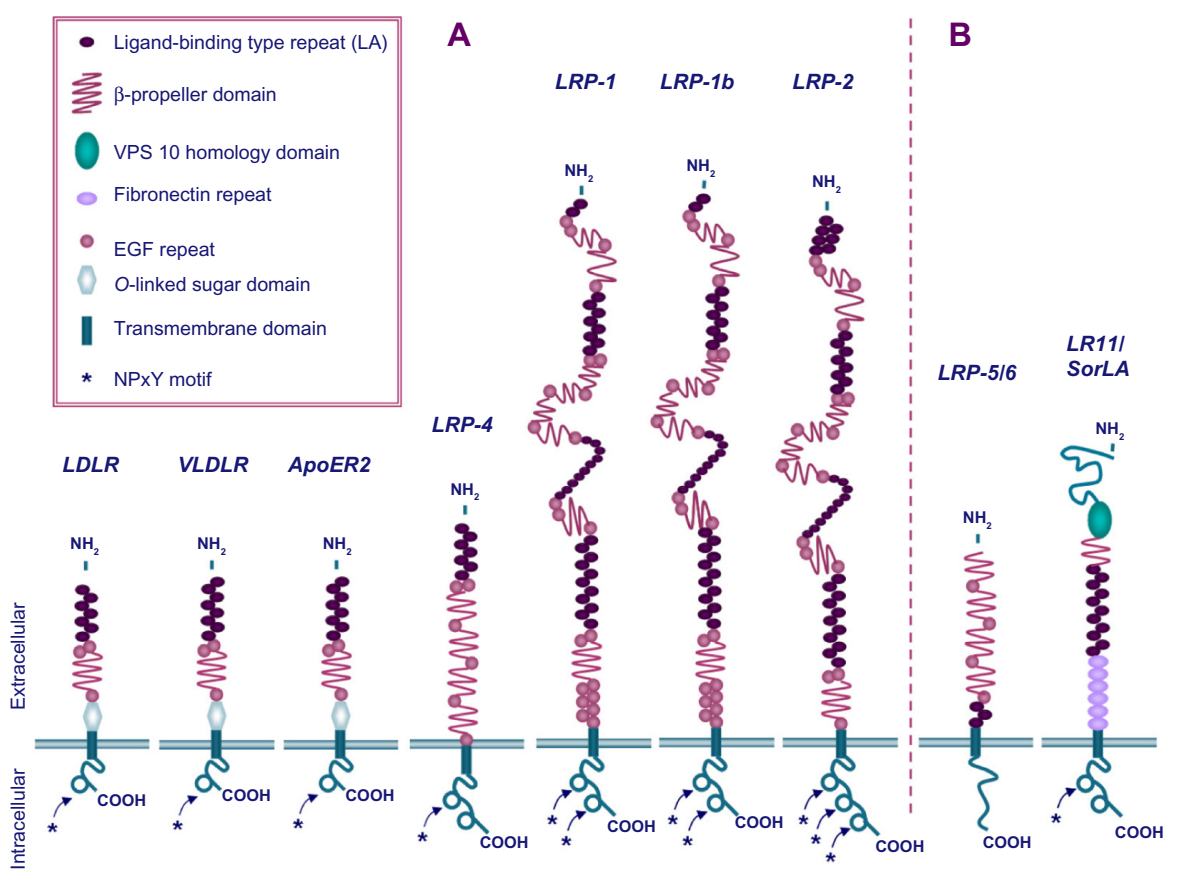

Figure I The low-density lipoprotein (LDL) receptor gene family.

Notes: (A) The core of the LDL receptor family consists of the LDL receptor (LDLR), VLDL receptor (VLDLR), apolipoprotein E receptor 2 (ApoER-2), LRP-4 (multiple epidermal growth factor containing protein 7; MEGF7), LRP-I, LRP-Ib, and LRP-2 (megalin). The extracellular domains consist of arrays of ligand-binding type repeats, always followed by epidermal growth factor precursor homology domains. All receptors are anchored in the plasma membrane by a single membrane-spanning segment and contain a short cytoplasmic tail. (B) Distantly related receptors LRP-5 and LRP-6, which do not contain NPxY motifs in their cytoplasmic tail, and LRII/SorLA, which harbors a VPSI0 homology domain and six fibronectin repeats.

Abbreviation: VLDL, very low-density lipoprotein. 


\section{MMP-2, MMP-9, and MMP-I3}

MMP-13 was the first metalloproteinase identified as ligand of LRP-1. ${ }^{23}$ This was based on the observation that the parathyroid hormone promotes clearance of rat collagenase (the ortholog of human collagenase-3 or MMP-13) from the culture medium conditioned by rat osteosarcoma cells. ${ }^{24}$ MMP-13 endocytosis is a two-step process of binding and internalization that requires both an unidentified $170 \mathrm{kDa}$ coreceptor and LRP-123 (Figure 2). The endocytosis of MMP-2 involves a preliminary association with a soluble partner, TSP- $2,{ }^{25}$ or TIMP- $2,{ }^{26}$ followed by recruitment by a membrane heparan sulfate proteoglycan for a MMP-2/TSP-2 complex or an unidentified coreceptor for MMP-2/TIMP-2. In contrast, endocytosis of MMP-9, whether complexed to TIMP- $1^{27}$ or not, ${ }^{28}$ results from a direct binding to LRP-1.

\section{ADAMTS-4 and ADAMTS-5}

ADAMTS-4 and ADAMTS-5 are considered major metalloproteinases that degrade the proteoglycan aggrecan in cartilage. ${ }^{29}$ They are both endocytosed by LRP-1 expressed by chondrocytes. ${ }^{30,31}$ The rate of endocytosis of ADAMTS-4 is slower than that of ADAMTS-5. Such a difference is explained by a 13-fold lower affinity of ADAMTS-4 for LRP-1 compared with that of ADAMTS-5.

\section{TIMP-I,TIMP-2, and TIMP-3}

TIMP-1 was first identified as an LRP-1 ligand only as a complex with MMP-9. ${ }^{27}$ However, using recombinant TIMP-1, we recently showed by surface plasmon resonance analysis that free TIMP-1 interacts directly with LRP-1 with high affinity. ${ }^{32}$ As with TIMP-1, TIMP-2, either as a complex with MMP-2 or as a free form, binds to and is internalized by LRP-1. ${ }^{26}$ The third member of the TIMP family, TIMP-3, has also been identified as an LRP-1 ligand. ${ }^{33,34}$

\section{LRP-2}

Another important and multifunctional member of the family is LRP-2 (also known as megalin and gp330). LRP-2 has a molecular mass of approximately $600 \mathrm{kDa}$ and contains 36 cysteine-rich ligand-binding domains, 16 EGF repeats, and 40 YWTD repeats in the extracellular domain. ${ }^{7}$ As with LRP-1, LRP-2 harbors four clusters of ligand-binding domains, allowing binding and internalization of a variety of ligands including proteinase/inhibitor complexes, vitamin/vitamin binding protein complexes, hormones, and lipoproteins. ${ }^{35}$ LRP-2 has in particular been recognized as a new functional endocytic receptor for MMP-9 clearance..$^{28}$ This receptor is expressed at the apical surface of epithelial cells, with the main site of expression being the proximal renal tubule, where LRP-2 functions as the major scavenger receptor.

\section{LRP-Ib}

LRP-1b, initially referred to as LRP-DIT (deleted in tumor), is a candidate tumor suppressor. ${ }^{6}$ LRP- $1 \mathrm{~b}$ and LRP-1 share several common features. Along with LRP-2, they are the largest known members of the LDL receptor family, with molecular masses around $600 \mathrm{kDa}$. Furthermore, both have four putative extracellular ligand-binding domains that are separated by clusters of EGF precursor repeats and propeller regions. The number and arrangement of these repeats are similar in both LRP-1 and LRP-1b, but LRP-1b contains one additional ligand-binding repeat in the ligand-binding domain IV, as well as an additional 33-amino acid sequence

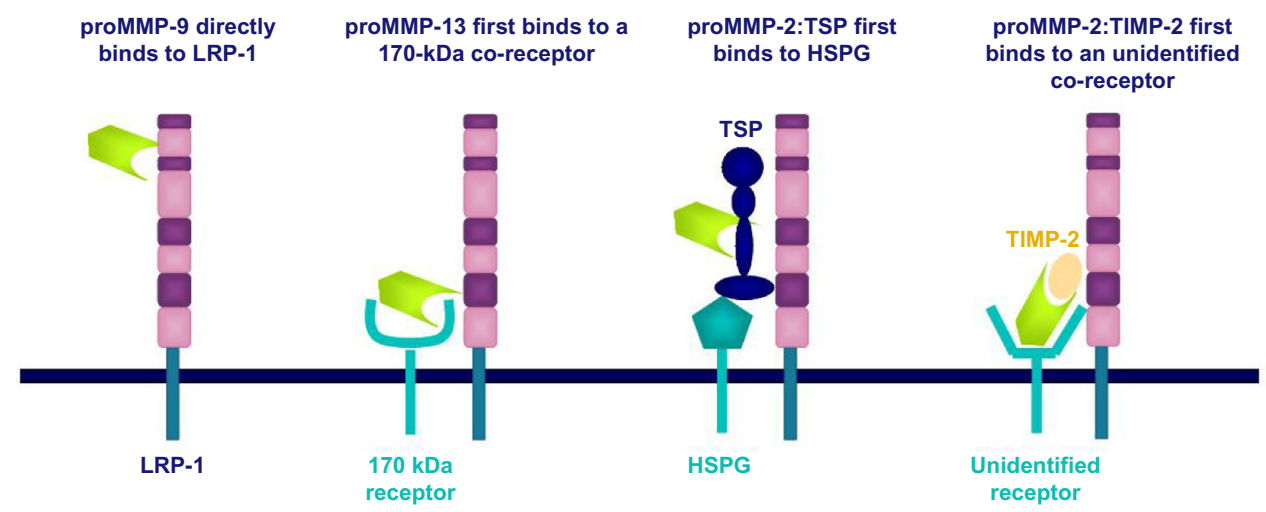

Figure 2 Different mechanisms of low-density lipoprotein receptor-related protein I (LRP-I)-mediated clearance of matrix metalloproteinases (MMPs).

Notes: The more straightforward mechanism is the direct association of proMMP-9 with LRP-I. ProMMP-I3 first binds to an unidentified I 70 kDa cell surface coreceptor before LRP-I-mediated endocytosis. LRP-I-mediated clearance of proMMP-2 involves two different coreceptors: if bound to thrombospondin (TSP), proMMP-2 first associates with an unknown cell surface heparan sulfate proteoglycan (HSPG) before interaction with LRP-I, and when complexed with TIMP-2, proMMP-2 first binds to an unidentified coreceptor. 
within its cytoplasmic tail. Although LRP-1 is found in all tissues, LRP-1b expression appears to be more limited, with preferential localization in brain, thyroid, and salivary glands. The function of LRP-1b is still largely unknown, but LRP-1b has several ligands common to LRP-1, including complexes of urokinase plasminogen activator/plasminogen activator inhibitor type 1. Furthermore, LRP-1b inactivation in thyroid cancer cells modifies the tumor microenvironment that promotes cell growth and invasive capacity. Restoration of LRP-1b impairs both in vitro and in vivo tumor growth, inhibits cell invasion, and leads to a reduction of MMP-2 in the conditioned medium without a difference in MMP-2 messenger (mRNA) levels. ${ }^{36}$ This data clearly indicates that LRP-1b mediates the endocytic clearance of MMP-2.

\section{Regulation of metalloproteinase activities through signaling function of members of the LDLR family}

In addition to its endocytic functions, LRP-1 also modulates metalloproteinase activity through signaling functions. Similarly, LRP-5 and LRP-6 appear to be associated with the modulation of metalloproteinase expression.

\section{LRP-I}

In addition to its endocytic function, LRP-1 also modulates metalloproteinase expression through its signaling function. Thus, binding of the serine protease tissue-type plasminogen activator to LRP-1 induces tyrosine phosphorylation of the $\beta$-chain cytoplasmic part and triggers intracellular signal transduction to induce MMP-9 expression in renal interstitial fibroblasts. ${ }^{37}$ Such an MMP-9 upregulation by tissue-type plasminogen activator binding to LRP-1 has also been demonstrated in brain, both in cell culture and in vivo. ${ }^{38}$ Rather surprisingly, binding of the serine protease inhibitor protease nexin-1 to LRP-1 stimulates extracellular signal-regulated kinase activation that results in increased MMP-9 mRNA levels in mammary tumor cells. ${ }^{39}$ In addition, LRP-1 silencing impeded glioblastoma cell migration and invasion by inhibiting MMP-2 and MMP-9 expression through a decreased level of phosphorylated extracellular signal-regulated kinase. ${ }^{40}$

\section{LRP-5}

LRP-5 exhibits the modules characteristic of the LDRL family. However, it has a unique organization of EGF and LDLR repeats, suggesting LRP-5 could represent a new category of the LDLR family (Figure 1). ${ }^{11}$ LRP-5 has been shown to be specifically required for $\mathrm{Wnt} / \beta$-catenin signaling. ${ }^{41}$
Interestingly, Wnt/LRP-5 interactions have been demonstrated to modulate the expression of various metalloproteinases, including MMP-2, ${ }^{42} \mathrm{MMP}-3,{ }^{43} \mathrm{MMP}-13,{ }^{44}$ and MMP-14. ${ }^{42}$

\section{LRP-6}

LRP-6 displays a pattern of four EGF and three LDLR repeats in the extracellular domain comparable with those of LRP-5, and consequently, it can be classified in the same new class of the LDLR family as LRP-5. ${ }^{12}$ As with LRP-5, LRP-6 interacts with Wnt. ${ }^{45}$ Transgenic mice overexpressing LRP-6 in mammary epithelial cells exhibit significant Wnt activation and upregulation of the expression of several MMPs, including MMP-2, MMP-3, MMP-7, MMP-9, MMP-13, and MMP-14. ${ }^{46}$ In contrast, another study revealed that the heterozygous loss-offunction mutation in LRP-6 gene in mice leads to less $\beta$-catenin signaling within articular cartilage and increased degenerative joint disease after ligament and meniscus injury associated with increased MMP-3 and MMP-13 expression. ${ }^{47}$

\section{Effect of metalloproteinase regulation by members of the LDLR family on pathologies}

\section{Focus on LRP-I}

As reviewed earlier, members of the LDLR family can, either positively or negatively, regulate metalloproteinase activity through their endocytic and/or signaling properties. Moreover, these receptors may themselves affect pathologies independent of metalloproteinase regulation. ${ }^{20,48}$ It is thus rather difficult to estimate their exact contribution in the development of metalloproteinase-mediated pathologies. As a consequence, this section is focused on the endocytic and signaling receptor LRP-1 through some examples selected among the main metalloproteinases-related pathologies.

\section{Neurological disorders}

Alzheimer's disease is a neurodegenerative disorder leading to dementia. The prevailing view of Alzheimer's disease pathogenesis posits that accumulation of amyloid- $\beta$ peptide $(A \beta)$, particularly $A \beta 42$, is the central event triggering neurodegeneration. ${ }^{49}$ It has been postulated that the development of amyloid plaques in $\mathrm{AD}$ may result from an imbalance between the generation and clearance of the A $\beta$. The amyloid precursor protein (APP) can be cleaved by metalloproteinases, precluding the production of $A \beta$ or contributing to the degradation of the neurotoxic peptide. ${ }^{50}$ Evidence suggests that metalloproteinases, and in particular MMPs and ADAMs, may process APP or A $\beta .{ }^{51}$ Among them, MMP-9 and ADAM-10 
cleave the $A \beta$ sequence in its middle, and this not only precludes its formation but also generates the secreted product sAPP $\alpha$ that possesses neurotrophic and neuroprotective properties. ${ }^{52,53}$ In addition, MMP-9 and MMP- 2 can proteolytically degrade the fibrillary forms of $A \beta 40$ and $42 .{ }^{51}$ However, such neuroprotective properties can be counterbalanced by TIMPs, particularly TIMP-1, which is largely produced by astrocytes surrounding the amyloid plaques. ${ }^{54}$ MMP-2 and MMP-9, as well as TIMP-1, TIMP-2, and TIMP-3, are all LRP-1 ligands (see preceding text). Moreover, TIMP-1 binding to LRP-1 expressed at the surface of neurons greatly impairs neurite growth, a hallmark of neurodegenerative disorders. ${ }^{32}$ From the point of view of metalloproteinase regulation, the role of LRP-1 in the development of Alzheimer's disease remains difficult to understand.

\section{Cancer}

Cancer progression is largely associated with the metalloproteinase-mediated breakdown of the extracellular matrix surrounding cancer cells. ${ }^{55}$ Thus, LRP-1 could act as a true tumor repressor by regulating metalloproteinase activity (as detailed above in the paragraph "Members of the LDLR family regulate metalloproteinase activity/Regulation of metalloproteinase activity by endocytosis/LRP-1"). In this sense, decreased expression of LRP-1 has been associated with tumor progression in numerous cancer types. ${ }^{56-59}$ By reducing MMP-2 levels in the microvasculature, LRP-1 improves the antiangiogenic activity of TSP- 2 in a murine glioma model ${ }^{60}$ In contrast, human malignant astrocytomas exhibit an increased LRP-1 expression. ${ }^{61}$ As pointed out earlier with regard to neurological disorders, the anticancer effect of LRP-1 related to its capacity of endocytosing metalloproteinases may be counterbalanced by its capacity to endocytose their inhibitors or by its protumor signaling properties. Thus, LRP-1 mediates MMP-2 and/or MMP-9 expression by tumor cells on various stimuli. ${ }^{37-40}$ In addition, LRP-1, whose expression is increased by hypoxia, ${ }^{62}$ regulates cancer cell survival and metastasis development. ${ }^{63}$ Finally, LRP-1 may promote tumor cell invasion both by regulating cytoskeleton organization and adhesive complex turnover ${ }^{64}$ and by internalizing the adhesion receptor $\mathrm{CD} 44 .{ }^{65}$

These opposite effects observed in vitro or in animal models also occur in humans, apparently depending on the organs. Thus, the $T$ allele of the C766T polymorphism in the LRP-1 gene has been associated with an increased risk for breast cancer development. ${ }^{66}$ LRP-1 overexpression has been also found in the highly aggressive Her-2/neu overexpressing and in triple-negative breast carcinomas ${ }^{67}$ In contrast, LRP-1 expression in stromal cells is associated with a favorable outcome in lung cancer. ${ }^{68}$

\section{Other metalloproteinase- mediated pathologies}

Vascular pathological conditions, such as atherosclerosis and aortic aneurysms, are characterized by intense metalloproteinase activities. ${ }^{69}$ MMP-2 and MMP-9 actively participate in the development of aneurysms ${ }^{70}$ through their capacity of degrading elastin, a main component of the elastic fibers in vascular walls. ${ }^{71}$ Interestingly, binding of activated $\alpha_{2}$-macroglobulin to LRP-1 increases MMP-9 expression by macrophages..$^{72}$ The main metalloproteinases involved in cartilage matrix degradation in osteoarthritis are MMP-13, for collagen degradation, and ADAMTS-4 and ADAMTS-5, for aggrecan degradation. ${ }^{73}$

\section{LRP-I: angel or devil?}

As illustrated earlier, LRP-1 may exert a protective effect by inhibiting the excess of extracellular metalloproteinases (eg, MMP-2 and MMP-9 in vascular pathologies and MMP-13, ADAMTS-4, and ADAMTS-5 in osteoarthritis). LRP-1 also exerts deleterious effects by eliminating metalloproteinase inhibitors (TIMP-1, TIMP-2, and TIMP-3). The signaling function exerted by LRP-1 further adds a supplemental level of difficulty for understanding the actual effect of this receptor in metalloproteinases-mediated pathologies.

\section{Metalloproteinases regulate members of the LDLR family by shedding their ectodomain}

The members of the LDLR family that regulate metalloproteinase activities by endocytic process, that is, LRP-1, LRP-1b, and LRP-2, are themselves controlled by metalloproteinases, which shed their ectodomain (ECD).

\section{LRP-I}

The presence of soluble LRP-1 ECD was first reported in human plasma. ${ }^{74}$ Further characterization of LRP-1 ECD in human choriocarcinoma cells revealed that soluble LRP-1 $\alpha$-chain copurified with a truncated $55-\mathrm{kDa} \beta$-chain, corresponding to the predicted molecular weight of the extracellular portion of the $\beta$-chain, meaning that LRP-1 shedding occurs by proteolytic cleavage close to the junction between the extracellular and the transmembrane domains. ${ }^{75}$ A metalloproteinase was responsible for LRP-1 ECD shedding in this model. A recent study reported the presence of soluble LRP-1 ECD in human brain tissue and cerebrospinal fluid. ${ }^{76}$ In this study, 
LRP-1 shedding was regulated by ADAM-10 and ADAM-17. We previously provided evidence that LRP-1 ECD shedding occurred in cultures of human endometrial explants. ${ }^{77} \mathrm{We}$ also characterized MT1-MMP and ADAM-12 as new sheddases of LRP-1 in the human fibrosarcoma HT1080 cell line. ${ }^{78}$

As with numerous transmembrane receptors, such as Notch, ${ }^{79}$ LRP-1 undergoes regulated intramembrane proteolysis. This sequential proteolytic process involves preliminary ECD shedding. This generates a substrate for a second protease system, generally a $\gamma$-secretase presenilin, which cleaves within the transmembrane domain and releases the intracellular domain (ICD) (Figure 3).

We also showed that the cholesterol content of plasma membrane was involved in the shedding of the ECD of LRP-1 and could influence its endocytic properties. ${ }^{78}$

\section{LRP-Ib and LRP-2}

In contrast to LRP-1, only a few data concerning the regulation of cell surface expression by shedding are available for LRP-1b and LRP-2. Thus, by using specific metalloproteinase inhibitors, Liu et al showed that LRP-1b ECD was shed by ADAM- $17 .{ }^{80}$
Immuno-ultrastructural studies revealed two forms of LRP-2 in the brush border of kidney proximal tubules. ${ }^{81}$ One of these forms, which lacked its cytoplasmic domain, was associated with the microvillar surface. These observations, which strongly suggested that LRP-2 can be proteolytically processed, were confirmed by in vitro studies demonstrating the shedding of LRP-2 ECD by unidentified metalloproteinases in an opossum kidney proximal tubule cell line. ${ }^{82}$

\section{Effect of shedding on metalloproteinase- mediated pathologies}

Increased LRP-1 shedding from human lung fibroblasts impairs endocytosis of MMP-2 and MMP-9, and thus might contribute to lung tissue destruction in acute respiratory distress syndrome. ${ }^{83}$ We similarly reported that the inhibition of LRP-1 shedding improves MMP-2 and MMP-9 clearance in cultures of human endometrial explants and may help prevent the occurrence of abnormal uterine bleeding. ${ }^{77}$ Importantly, LRP-1 ECD retains ligand-binding capacity and acts as a decoy receptor. ${ }^{84}$ Thus, the addition of LRP-1 ECD to cultured rat hepatocytes resulted in the inhibition of tissue-type plasminogen activator clearance. ${ }^{74}$ We recently

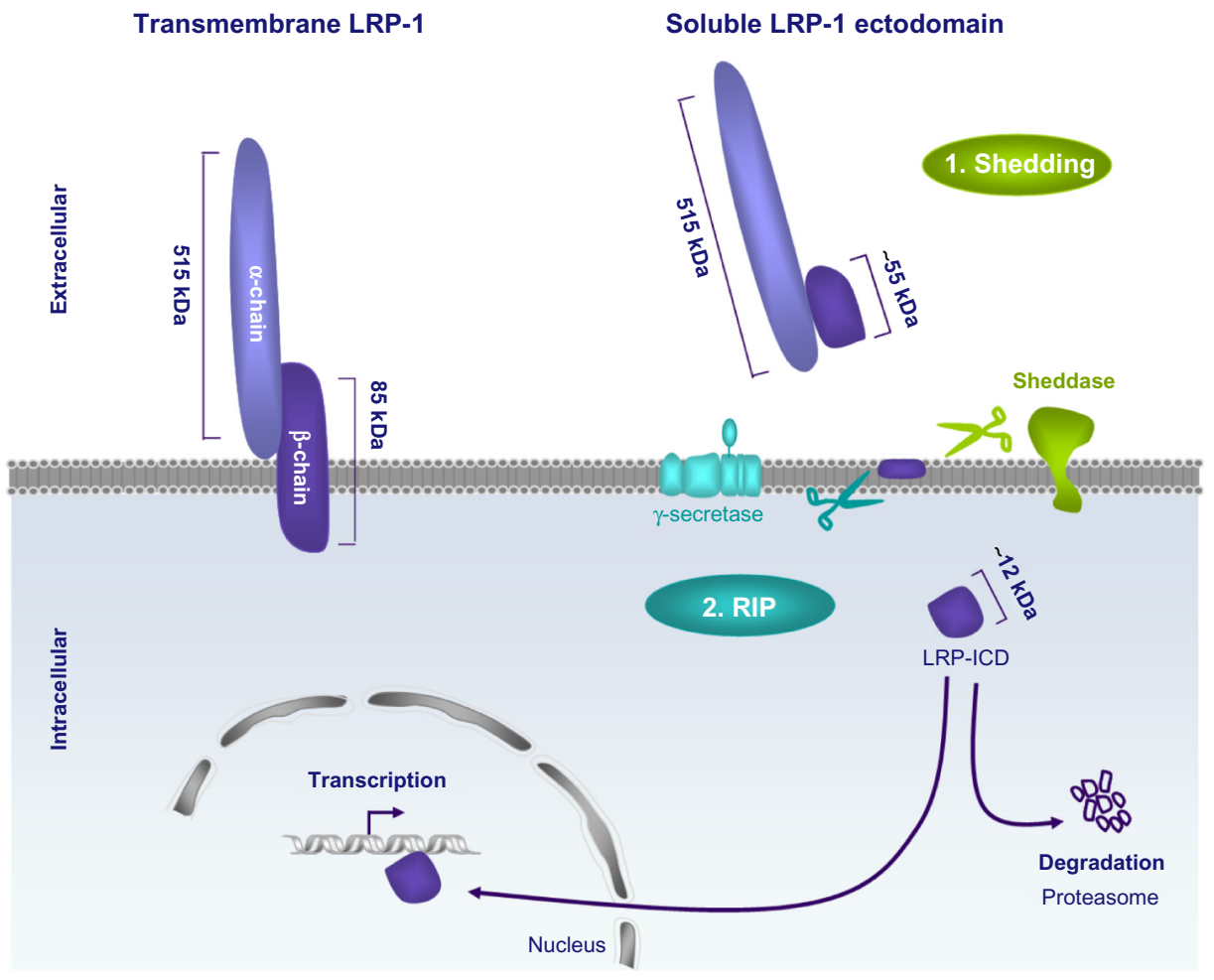

Figure 3 Low-density receptor-related protein I (LRP-I) ectodomain shedding and regulated intramembrane proteolysis.

Notes: LRP-I undergoes a cleavage by a proteolytic enzyme in the extracellular domain of its $\beta$-chain, leading to the release of its ectodomain. After this shedding, LRP-I undergoes a $\gamma$-secretase-dependent intramembrane cleavage of the $25 \mathrm{kDa}$ membrane-bound $\beta$ chain, leading to the release of the intracellular domain (LRP-ICD), a fragment of approximately $12 \mathrm{kDa}$. This process, called regulated intramembrane proteolysis (RIP), may in some cases be coupled with nuclear signaling, as previously reported for Notch and amyloid precursor protein. 
demonstrated that TIMP-3 bound to LRP-1 ECD became resistant to endocytosis and retained its inhibitory activity against metalloproteinases. ${ }^{34}$ Although no experimental data exist concerning the binding of metalloproteinases; of their inhibitors TIMP-1 and TIMP-2 to LRP-1 ECD; or of MMP-9 to LRP-2 ECD and the preservation of their activities, it is tempting to attribute to these ECDs a role in the development of pathologies associated with excessive inflammation. In this sense, LRP-1 ECD levels are increased in the plasma of patients with rheumatoid arthritis and osteoarthritis. ${ }^{85}$ In addition, the increased levels of LRP-1 ECD in the cerebrospinal fluid of old individuals suggest that LRP-1 shedding during aging could contribute to the pathogenesis of Alzheimer's disease. ${ }^{76}$

The ICD generated by shedding of Notch translocates to the nucleus for regulating transcription of target genes. ${ }^{86}$ In vitro studies showed that similar to Notch ICD, LRP-1 ICD is translocated to the nucleus. ${ }^{87}$ It has been described as impairing the transcriptional activity of APP, Fe65, and Tip60 complex. ${ }^{88}$ In neurons, LRP-1 ICD translocation to the nucleus leads to apoptotic cell death in ischemic conditions. ${ }^{89}$ In macrophages, LRP-1 ICD represses the interferon- $\gamma$ promoter and limits the inflammatory response. ${ }^{90}$ Blocking of LRP-1b ICD release impedes the ability of LRP-1b to suppress anchorage-independent growth in a cell line derived from a human central nervous system tumor. ${ }^{80}$

These data highlight putative roles exerted by ECD and ICD from members of the LDLR family in the development of metalloproteinase-mediated pathologies.

\section{Conclusion}

After presenting the different members of the LDLR family involved in the regulation of metalloproteinase activities, we focused this review on LRP-1 and its involvement in the main metalloproteinase-mediated pathologies that are Alzheimer's disease, cancer, vascular diseases, and osteoarthritis. By coupling endocytosis with cell signaling, LRP-1 appears to be an efficient cell surface receptor that allows a rapid answer to a modification of the cell microenvironment.

Understanding the pathways regulated by LRP-1 in the metalloproteinase-mediated pathologies represents an important challenge for providing adequate responses to patients.

\section{Acknowledgments}

We thank Dr Charlotte Selvais for her help in preparing figures. HE is supported by the Universite de Reims Champagne-Ardenne and the Centre National de la Recher- che Scientifique, France. EM is supported by the Université catholique de Louvain.

\section{Disclosure}

The authors report no conflicts of interest in this work.

\section{References}

1. Nagase H, Visse R, Murphy G. Structure and function of matrix metalloproteinases and TIMPs. Cardiovasc Res. 2006;69(3):562-573.

2. Blacklow SC. Versatility in ligand recognition by LDL receptor family proteins: advances and frontiers. Curr Opin Struct Biol. 2007;17(4): 419-426.

3. Brown MS, Goldstein JL. A receptor-mediated pathway for cholesterol homeostasis. Science. 1986;232(4746):34-47.

4. van Dijk MC, Kruijt JK, Boers W, Linthorst C, van Berkel TJ. Distinct properties of the recognition sites for beta-very low density lipoprotein (remnant receptor) and alpha 2-macroglobulin (low density lipoprotein receptor-related protein) on rat parenchymal cells. $J$ Biol Chem. 1992;267(25):17732-17737.

5. Herz J, Hamann U, Rogne S, Myklebost O, Gausepohl H, Stanley KK. Surface location and high affinity for calcium of a 500-kd liver membrane protein closely related to the LDL-receptor suggest a physiological role as lipoprotein receptor. EMBO J. 1988;7(13):4119-4127.

6. Liu CX, Li Y, Obermoeller-McCormick LM, Schwartz AL, Bu G. The putative tumor suppressor LRP1B, a novel member of the low density lipoprotein (LDL) receptor family, exhibits both overlapping and distinct properties with the LDL receptor-related protein. $J$ Biol Chem. 2001;276(31):28889-28896.

7. Stefansson S, Chappell DA, Argraves KM, Strickland DK, Argraves WS Glycoprotein 330/low density lipoprotein receptor-related protein-2 mediates endocytosis of low density lipoproteins via interaction with apolipoprotein B100. J Biol Chem. 1995;270(33):19417-19421.

8. Ishii H, Kim DH, Fujita T, Endo Y, Saeki S, Yamamoto TT. cDNA cloning of a new low-density lipoprotein receptor-related protein and mapping of its gene (LRP3) to chromosome bands 19q12-q13. 2 . Genomics. 1998;51(1):132-135.

9. Battle MA, Maher VM, McCormick JJ. ST7 is a novel low-density lipoprotein receptor-related protein (LRP) with a cytoplasmic tail that interacts with proteins related to signal transduction pathways. Biochemistry. 2003;42(24):7270-7282.

10. Tomita Y, Kim DH, Magoori K, Fujino T, Yamamoto TT. A novel low-density lipoprotein receptor-related protein with type II membrane protein-like structure is abundant in heart. $J$ Biochem. 1998;124(4): 784-789.

11. Hey PJ, Twells RC, Phillips MS, et al. Cloning of a novel member of the low-density lipoprotein receptor family. Gene. 1998;216(1): $103-111$.

12. Brown SD, Twells RC, Hey PJ, et al. Isolation and characterization of LRP6, a novel member of the low density lipoprotein receptor gene family. Biochem Biophys Res Commun. 1998;248(3):879-888.

13. Chen D, Lathrop W, Dong Y. Molecular cloning of mouse Lrp7(Lr3) cDNA and chromosomal mapping of orthologous genes in mouse and human. Genomics. 1999;55(3):314-321.

14. Riddell DR, Vinogradov DV, Stannard AK, Chadwick N, Owen JS. Identification and characterization of LRP8 (apoER2) in human blood platelets. J Lipid Res. 1999;40(10):1925-1930.

15. Sugiyama T, Kumagai H, Morikawa Y, et al. A novel low-density lipoprotein receptor-related protein mediating cellular uptake of apolipoprotein E-enriched beta-VLDL in vitro. Biochemistry. 2000;39(51): $15817-15825$

16. Jeong $\mathrm{YH}$, Ishikawa $\mathrm{K}$, Someya $\mathrm{Y}$, et al. Molecular characterization and expression of the low-density lipoprotein receptor-related protein-10, a new member of the LDLR gene family. Biochem Biophys Res Commun. 2010;391(1):1110-1115. 
17. Yamazaki H, Bujo H, Saito Y. A novel member of the LDL receptor gene family with eleven binding repeats is structurally related to neural adhesion molecules and a yeast vacuolar protein sorting receptor. J Atheroscler Thromb. 1997;4(1):20-26.

18. Schneider WJ. The low density lipoprotein receptor. Biochim Biophys Acta. 1989;988(2):303-317.

19. Kristensen T, Moestrup SK, Gliemann J, Bendtsen L, Sand O, SottrupJensen L. Evidence that the newly cloned low-density-lipoprotein receptor related protein (LRP) is the alpha 2-macroglobulin receptor. FEBS Lett. 1990;276(1-2):151-155.

20. Lillis AP, Van Duyn LB, Murphy-Ullrich JE, Strickland DK. LDL receptor-related protein 1: unique tissue-specific functions revealed by selective gene knockout studies. Physiol Rev. 2008;88(3):887-918.

21. Emonard H, Théret L, Bennasroune AH, Dedieu S. Regulation of LRP-1 expression: make the point. Pathol Biol (Paris). 2014;62(2):84-90.

22. Etique N, Verzeaux L, Dedieu S, Emonard H. LRP-1: a checkpoint for the extracellular matrix proteolysis. Biomed Res Int. 2013;2013:152163.

23. Barmina OY, Walling HW, Fiacco GJ, et al. Collagenase-3 binds to a specific receptor and requires the low density lipoprotein receptorrelated protein for internalization. J Biol Chem. 1999;274(42): 30087-30093.

24. Partridge NC, Jeffrey JJ, Ehlich LS, et al. Hormonal regulation of the production of collagenase and a collagenase inhibitor activity by rat osteogenic sarcoma cells. Endocrinology. 1987;120(5):1956-1962.

25. Yang Z, Strickland DK, Bornstein P. Extracellular matrix metalloproteinase 2 levels are regulated by the low density lipoproteinrelated scavenger receptor and thrombospondin 2.J Biol Chem. 2001; 276(11):8403-8408.

26. Emonard H, Bellon G, Troeberg L, et al. Low density lipoprotein receptor-related protein mediates endocytic clearance of pro-MMP-2. TIMP-2 complex through a thrombospondin-independent mechanism. J Biol Chem. 2004;279(52):54944-54951.

27. Hahn-Dantona E, Ruiz JF, Bornstein P, Strickland DK. The low density lipoprotein receptor-related protein modulates levels of matrix metalloproteinase 9 (MMP-9) by mediating its cellular catabolism. J Biol Chem. 2001;276(18):15498-15503.

28. Van den Steen PE, Van Aelst I, Hvidberg V, et al. The hemopexin and O-glycosylated domains tune gelatinase B/MMP-9 bioavailability via inhibition and binding to cargo receptors. J Biol Chem. 2006;281(27): 18626-18637.

29. Gendron C, Kashiwagi M, Lim NH, et al. Proteolytic activities of human ADAMTS-5: comparative studies with ADAMTS-4. J Biol Chem. 2007;282(25):18294-18306.

30. Yamamoto K, Owen K, Parker AE, et al. Low density lipoprotein receptor-related protein 1 (LRP1)-mediated endocytic clearance of a disintegrin and metalloproteinase with thrombospondin motifs-4 (ADAMTS-4): functional differences of non-catalytic domains of ADAMTS-4 and ADAMTS-5 in LRP1 binding. $J$ Biol Chem. 2014; 289(10):6462-6474.

31. Yamamoto K, Troeberg L, Scilabra SD, et al. LRP-1-mediated endocytosis regulates extracellular activity of ADAMTS-5 in articular cartilage. FASEB J. 2013;27(2):511-521.

32. Thevenard J, Verzeaux L, Devy J, et al. Low-density lipoprotein receptor-related protein-1 mediates endocytic clearance of tissue inhibitor of metalloproteinases-1 and promotes its cytokine-like activities. PLoS ONE. 2014;9(7):e103839.

33. Troeberg L, Fushimi K, Khokha R, Emonard H, Ghosh P, Nagase H. Calcium pentosan polysulfate is a multifaceted exosite inhibitor of aggrecanases. FASEB J. 2008;22(10):3515-3524.

34. Scilabra SD, Troeberg L, Yamamoto K, et al. Differential regulation of extracellular tissue inhibitor of metalloproteinases-3 levels by cell membrane-bound and shed low density lipoprotein receptor-related protein 1. J Biol Chem. 2013;288(1):332-342.

35. Marzolo MP, Farfán P. New insights into the roles of megalin/LRP2 and the regulation of its functional expression. Biol Res. 2011;44(1): $89-105$.
36. Prazeres H, Torres J, Rodrigues F, et al. Chromosomal, epigenetic and microRNA-mediated inactivation of LRP1B, a modulator of the extracellular environment of thyroid cancer cells. Oncogene. 2011;30(11): 1302-1317.

37. Hu K, Yang J, Tanaka S, Gonias SL, Mars WM, Liu Y. Tissue-type plasminogen activator acts as a cytokine that triggers intracellular signal transduction and induces matrix metalloproteinase-9 gene expression. J Biol Chem. 2006;281(4):2120-2127.

38. Wang X, Lee SR, Arai K, et al. Lipoprotein receptor-mediated induction of matrix metalloproteinase by tissue plasminogen activator. Nat Med. 2003;9(10):1313-1317.

39. Fayard B, Bianchi F, Dey J, et al. The serine protease inhibitor protease nexin-1 controls mammary cancer metastasis through LRP-1-mediated MMP-9 expression. Cancer Res. 2009;69(14):5690-5698.

40. Song H, Li Y, Lee J, Schwartz AL, Bu G. Low-density lipoprotein receptor-related protein 1 promotes cancer cell migration and invasion by inducing the expression of matrix metalloproteinases 2 and 9 . Cancer Res. 2009;69(3):879-886.

41. Wehrli M, Dougan ST, Caldwell K, et al. Arrow encodes an LDLreceptor-related protein essential for Wingless signalling. Nature. 2000; 407(6803):527-530.

42. Guo Y, Zi X, Koontz Z, et al. Blocking Wnt/LRP5 signaling by a soluble receptor modulates the epithelial to mesenchymal transition and suppresses met and metalloproteinases in osteosarcoma Saos-2 cells. J Orthop Res. 2007;25(7):964-971.

43. Ozeki N, Hase N, Hiyama T, et al. IL-1 $\beta$-induced, matrix metalloproteinase-3-regulated proliferation of embryonic stem cell-derived odontoblastic cells is mediated by the Wnt5 signaling pathway. Exp Cell Res. 2014;328(1):69-86.

44. Papathanasiou I, Malizos KN, Tsezou A. Low-density lipoprotein receptor-related protein 5 (LRP5) expression in human osteoarthritic chondrocytes. J Orthop Res. 2010;28(3):348-353.

45. Tamai K, Semenov M, Kato Y, et al. LDL-receptor-related proteins in Wnt signal transduction. Nature. 2000;407(6803):530-535.

46. Zhang J, Li Y, Liu Q, Lu W, Bu G. Wnt signaling activation and mammary gland hyperplasia in MMTV-LRP6 transgenic mice: implication for breast cancer tumorigenesis. Oncogene. 2010;29(4): 539-549.

47. Joiner DM, Less KD, Van Wieren EM, Hess D, Williams BO. Heterozygosity for an inactivating mutation in low-density lipoproteinrelated receptor 6 (Lrp6) increases osteoarthritis severity in mice after ligament and meniscus injury. Osteoarthritis Cartilage. 2013;21(10): $1576-1585$

48. Gonias SL, Campana WM. LDL receptor-related protein-1: a regulator of inflammation in atherosclerosis, cancer, and injury to the nervous system. Am J Pathol. 2014;184(1):18-27.

49. Standridge JB. Vicious cycles within the neuropathophysiologic mechanisms of Alzheimer's disease. Curr Alzheimer Res. 2006;3(2): 95-108.

50. Makarova A, Williams SE, Strickland DK. Proteases and lipoprotein receptors in Alzheimer's disease. Cell Biochem Biophys. 2004; 41(1):139-178.

51. Rosenberg GA. Matrix metalloproteinases and their multiple roles in neurodegenerative diseases. Lancet Neurol. 2009;8(2):205-216.

52. Fragkouli A, Papatheodoropoulos C, Georgopoulos S, et al. Enhanced neuronal plasticity and elevated endogenous sAPP $\alpha$ levels in mice over-expressing MMP9. J Neurochem. 2012;121(2):239-251.

53. Colciaghi F, Borroni B, Pastorino L, et al. [alpha]-Secretase ADAM10 as well as [alpha]APPs is reduced in platelets and CSF of Alzheimer disease patients. Mol Med. 2002;8(2):67-74.

54. Rivera S, Ogier C, Jourquin J, et al. Gelatinase B and TIMP-1 are regulated in a cell- and time-dependent manner in association with neuronal death and glial reactivity after global forebrain ischemia. Eur J Neurosci. 2002;15(1):19-32.

55. Kessenbrock K, Plaks V, Werb Z. Matrix metalloproteinases: regulators of the tumor microenvironment. Cell. 2010;141(1):52-67. 
56. Kancha RK, Stearns ME, Hussain MM. Decreased expression of the low density lipoprotein receptor-related protein/alpha 2-macroglobulin receptor in invasive cell clones derived from human prostate and breast tumor cells. Oncol Res. 1994;6(8):365-372.

57. de Vries TJ, Verheijen JH, de Bart AC, Weidle UH, Ruiter DJ, van Muijen GN. Decreased expression of both the low-density lipoprotein receptor-related protein/alpha(2)-macroglobulin receptor and its receptor-associated protein in late stages of cutaneous melanocytic tumor progression. Cancer Res. 1996;56(6):1432-1439.

58. Gilardoni MB, Ceschin DG, Sahores MM, Oviedo M, Gehrau RC, Chiabrando GA. Decreased expression of the low-density lipoprotein receptor-related protein-1 (LRP-1) in rats with prostate cancer. J Histochem Cytochem. 2003;51(12):1575-1580.

59. Desrosiers RR, Rivard ME, Grundy PE, Annabi B. Decrease in LDL receptor-related protein expression and function correlates with advanced stages of Wilms tumors. Pediatr Blood Cancer. 2006;46(1): 40-49.

60. Fears CY, Grammer JR, Stewart JE Jr, et al. Low-density lipoprotein receptor-related protein contributes to the antiangiogenic activity of thrombospondin-2 in a murine glioma model. Cancer Res. 2005;65(20): 9338-9346.

61. Yamamoto M, Ikeda K, Ohshima K, Tsugu H, Kimura H, Tomonaga M. Increased expression of low density lipoprotein receptor-related protein/ alpha2-macroglobulin receptor in human malignant astrocytomas Cancer Res. 1997;57(13):2799-2805.

62. Koong AC, Denko NC, Hudson KM, et al. Candidate genes for the hypoxic tumor phenotype. Cancer Res. 2000;60(4):883-887.

63. Montel V, Gaultier A, Lester RD, Campana WM, Gonias SL. The low-density lipoprotein receptor-related protein regulates cancer cell survival and metastasis development. Cancer Res. 2007;67(20): 9817-9824.

64. Dedieu S, Langlois B, Devy J, et al. LRP-1 silencing prevents malignant cell invasion despite increased pericellular proteolytic activities. Mol Cell Biol. 2008;28(9):2980-2995.

65. Perrot G, Langlois B, Devy J, et al. LRP-1 - CD44, a new cell surface complex regulating tumor cell adhesion. Mol Cell Biol. 2012;32(16): 3293-3307.

66. Benes P, Jurajda M, Zaloudík J, Izakovicová-Hollá L, Vácha J. C766T low-density lipoprotein receptor-related protein 1 (LRP1) gene polymorphism and susceptibility to breast cancer. Breast Cancer Res. 2003; 5(3):R77-R81.

67. Catasus L, Gallardo A, Llorente-Cortes V, et al. Low-density lipoprotein receptor-related protein 1 is associated with proliferation and invasiveness in Her-2/neu and triple-negative breast carcinomas. Hum Pathol. 2011;42(11):1581-1588

68. Meng H, Chen G, Zhang X, et al. Stromal LRP1 in lung adenocarcinoma predicts clinical outcome. Clin Cancer Res. 2011;17(8):2426-2433.

69. Xu J, Shi GP. Vascular wall extracellular matrix proteins and vascular diseases. Biochim Biophys Acta. 2014;1842(11):2106-2119.

70. Longo GM, Xiong W, Greiner TC, Zhao Y, Fiotti N, Baxter BT. Matrix metalloproteinases 2 and 9 work in concert to produce aortic aneurysms. J Clin Invest. 2002;110(5):625-632.

71. Hornebeck W, Emonard H. The cell-elastin-elastase(s) interacting triade directs elastolysis. Front Biosci (Landmark Ed). 2011;16(1): 707-722.

72. Cáceres LC, Bonacci GR, Sánchez MC, Chiabrando GA. Activated $\alpha(2)$ macroglobulin induces matrix metalloproteinase 9 expression by lowdensity lipoprotein receptor-related protein 1 through MAPK-ERK1/2 and NF- $\kappa \mathrm{B}$ activation in macrophage-derived cell lines. $J$ Cell Biochem. 2010;111(3):607-617.
73. Troeberg L, Nagase H. Proteases involved in cartilage matrix degradation in osteoarthritis. Biochim Biophys Acta. 2012;1824(1):133-145.

74. Quinn KA, Grimsley PG, Dai YP, Tapner M, Chesterman CN, Owensby DA. Soluble low density lipoprotein receptor-related protein (LRP) circulates in human plasma. J Biol Chem. 1997;272(38): 23946-23951.

75. Quinn KA, Pye VJ, Dai YP, Chesterman CN, Owensby DA. Characterization of the soluble form of the low density lipoprotein receptor-related protein (LRP). Exp Cell Res. 1999;251(2):433-441.

76. Liu Q, Zhang J, Tran H, et al. LRP1 shedding in human brain: roles of ADAM10 and ADAM17. Mol Neurodegener. 2009;4(1):17.

77. Selvais C, Gaide Chevronnay HP, Lemoine P, et al. Metalloproteinasedependent shedding of low-density lipoprotein receptor-related protein-1 ectodomain decreases endocytic clearance of endometrial matrix metalloproteinase-2 and -9 at menstruation. Endocrinology. 2009; 150(8):3792-3799.

78. Selvais C, D'Auria L, Tyteca D, et al. Cell cholesterol modulates metalloproteinase-dependent shedding of low-density lipoprotein receptor-related protein-1 (LRP-1) and clearance function. FASEB J. 2011;25(8):2770-2781.

79. De Strooper B, Annaert W, Cupers P, et al. A presenilin-1-dependent gamma-secretase-like protease mediates release of Notch intracellular domain. Nature. 1999;398(6727):518-522.

80. Liu CX, Ranganathan S, Robinson S, Strickland DK. gammaSecretase-mediated release of the low density lipoprotein receptor-related protein 1B intracellular domain suppresses anchorage-independent growth of neuroglioma cells. J Biol Chem. 2007;282(10):7504-7511.

81. Bachinsky DR, Zheng G, Niles JL, et al. Detection of two forms of GP330. Their role in Heymann nephritis. Am J Pathol. 1993;143(2): 598-611.

82. Zou Z, Chung B, Nguyen T, Mentone S, Thomson B, Biemesderfer D. Linking receptor-mediated endocytosis and cell signaling: evidence for regulated intramembrane proteolysis of megalin in proximal tubule. J Biol Chem. 2004;279(33):34302-34310.

83. Wygrecka M, Wilhelm J, Jablonska E, et al. Shedding of low-density lipoprotein receptor-related protein-1 in acute respiratory distress syndrome. Am J Respir Crit Care Med. 2011;184(4):438-448.

84. Grimsley PG, Quinn KA, Owensby DA. Soluble low-density lipoprotein receptor-related protein. Trends Cardiovasc Med. 1998;8(8): 363-368.

85. Gorovoy M, Gaultier A, Campana WM, Firestein GS, Gonias SL. Inflammatory mediators promote production of shed LRP1/CD91, which regulates cell signaling and cytokine expression by macrophages. J Leukoc Biol. 2010;88(4):769-778.

86. Artavanis-Tsakonas S, Rand MD, Lake RJ. Notch signaling: cell fate control and signal integration in development. Science. 1999;284(5415): 770-776.

87. May P, Reddy YK, Herz J. Proteolytic processing of low density lipoprotein receptor-related protein mediates regulated release of its intracellular domain. J Biol Chem. 2002;277(21):18736-18743.

88. Kinoshita A, Shah T, Tangredi MM, Strickland DK, Hyman BT. The intracellular domain of the low density lipoprotein receptor-related protein modulates transactivation mediated by amyloid precursor protein and Fe65. J Biol Chem. 2003;278(42):41182-41188.

89. Polavarapu R, An J, Zhang C, Yepes M. Regulated intramembrane proteolysis of the low-density lipoprotein receptor-related protein mediates ischemic cell death. Am J Pathol. 2008;172(5):1355-1362.

90. Zurhove K, Nakajima C, Herz J, Bock HH, May P. Gamma-secretase limits the inflammatory response through the processing of LRP1. Sci Signal. 2008;1(47):ra15. 
Metalloproteinases In Medicine

Dovepress

\section{Publish your work in this journal}

Metalloproteinases In Medicine is an international, peer reviewed, open access journal that aims to provide a platform for the discussion and dissemination of knowledge about the role that metalloproteinases - such as matrix metalloproteinases (MMP), ADAMs, ADAMTSs, and astacins, as well as their inhibitors - play in diseases.

The manuscript management system is completely online and includes a very quick and fair peer review system, which is all easy to use. Visit http://www.dovepress.com/testimonials.php to read real quotes from published authors.

Submit your manuscript here: http://www.dovepress.com/metalloproteinases-in-medicine-journal 